\title{
Lipopolysaccharide and dose of nicotine determine the effects of nicotine on murine bone marrow-derived dendritic cells
}

\author{
SU XIAN HU ${ }^{1 *}$, HUA XIU SUI ${ }^{2 *}$, HAO JIE JIN ${ }^{2}$, XIAO YAN NI ${ }^{2}$, XIAO XING LIU ${ }^{2}$, \\ MAO QIANG XUE ${ }^{2}$, YE ZHANG ${ }^{2}$ and FENG GUANG GAO ${ }^{2}$ \\ ${ }^{1}$ Department of Respiratory Medicine, The First Affiliated Hospital of Xiamen University, Xiamen 361003; \\ ${ }^{2}$ Department of Immunology, Basic Medicine Science, Medical College, Xiamen University, Xiamen 361005, P.R. China
}

Received October 1, 2011; Accepted December 19, 2011

DOI: $10.3892 / \mathrm{mmr} .2012 .751$

\begin{abstract}
The reported effects of nicotine on dendritic cells (DCs) are controversial. To investigate the factors which determine the effects of nicotine on DCs, immature dendritic cells (imDCs) induced from murine bone marrow were treated with different doses of nicotine with or without lipopolysaccharides (LPS). The morphology and expression of the co-stimulatory molecules CD80, CD86, CD40 and CD54 were observed and determined by microscopy and flow cytometry, respectively. The results showed that, firstly, nicotine treatment promoted the development of DC precursors into imDCs with a semimature phenotype revealed by a higher expression of CD11c and more branched projections. Secondly, lower doses of nicotine $(16.5 \mathrm{ng} / \mathrm{ml})$, but not higher $(200 \mu \mathrm{g} / \mathrm{ml})$, up-regulated the expression of the co-stimulatory molecules CD80, CD40 and CD54 on imDCs. Co-administration of LPS and nicotine revealed differential effects on co-stimulatory molecule expression on imDCs. Thirdly and importantly, treatment with lower doses of nicotine $(16.5 \mathrm{ng} / \mathrm{ml})$ did not augment expression of the CD80, CD86, CD40 and CD54 molecules in mature DCs. Fourthly and interestingly, high doses of nicotine (more than $165 \mu \mathrm{g} / \mathrm{ml}$ ) revealed pro-apoptotic activity but lower doses of nicotine $(16.5-0.165 \mathrm{ng} / \mathrm{ml})$ achieved an antiapoptotic effect on imDCs. All data presented here indicate that the controversial effects of nicotine on DCs may be due to the LPS of the nicotinic environment and the dose of nicotine used.
\end{abstract}

Correspondence to: Professor Feng Guang Gao or Dr Ye Zhang, Department of Immunology, Basic Medicine Science, Medical College, Xiamen University, Xiamen 361005, P.R. China

E-mail: gfengguang@xmu.edu.cn

*Contributed equally

Abbreviations: DCs, dendritic cells; imDCs, immature dendritic cells; maDCs, mature dendritic cells; $\mathrm{nAChR}$, nicotinic acetylcholine receptor; $\mathrm{Ni}$, nicotine

Key words: nicotine, dendritic cells, lipopolysaccharides, co-stimulatory molecules

\section{Introduction}

Nicotine, a major component of cigarette smoke, unequivocally, has positive effects on illnesses as diverse as neurodegenerative diseases, ulcerative colitis and Tourette syndrome (1-3). Although the expression of nicotinic acetylcholine receptor (nACh) has been demonstrated in many types of non-neuronal cells such as dendritic cells (DCs), epithelial and endothelial cells (4), the effect of nicotine on immune cells is incompletely characterized. Aicher et al found that nicotine activates DCs and augments their capacity to stimulate $\mathrm{T}$ cell proliferation and cytokine secretion, which may contribute to the progression of atherosclerotic lesions (5). Our previous studies further demonstrated that nicotine has stimulatory effects on immature dendritic cells (imDCs), which reveal anti-tumor effects on lymphoma development (6), lung and liver cancer (7). Nouri-Shirazi et al reported that nicotine exerts immunosuppressive effects on immune surveillance through functional impairment of the DC system (8). In parallel with differential expression of costimulatory molecules CD80 and CD86 and lack of IL-12, nicotine-stimulated DCs displayed profoundly reduced Th1-promoting capacity (4), which recently confirmed that the presence of nicotine in the microenvironment promoted the development of mouse bone marrow-derived DC precursors into DCs with a semi-mature phenotype revealed by higher expression of costimulatory molecules CD80, CD86, CD40 and MHC II (9). Investigators have shown that nicotine promotes immune cell activation (5-7), whereas others have suggested that nicotine may have immunosuppressive effects on DCs $(4,8,9)$. Since the biological effect of nicotine on lymphocytes is dependent on dose and duration of exposure (10), the controversial effects of nicotine on DCs may be attributed to differences in experimental design, species, duration of exposure, particularly the nicotine concentration used in these experiments. Hence, further studies are needed to explore the factors which dictate the effects of nicotine on DCs.

In the present study, we first found that nicotine treatment up-regulated CD11c expression on imDCs in the absence of LPS, and secondly that lower and higher doses of nicotine used in previous reports up- or down-regulated the expression of co-stimulatory molecules on imDCs. Co-administration of LPS and nicotine revealed differential effects of expres- 
sion of the co-stimulatory molecules on imDCs. Thirdly and importantly, lower doses of nicotine treatment did not augment expression of CD80, CD86, CD40 and CD54 molecules on mature DCs. Fourthly and interestingly, high doses of nicotine (more than $165 \mu \mathrm{g} / \mathrm{ml}$ ) revealed pro-apoptotic activity and lower doses of nicotine $(16.5-0.165 \mathrm{ng} / \mathrm{ml})$ achieved an antiapoptotic effect on imDCs. These data presented here indicate that the controversial effects of nicotine on DCs may be due to the nicotinic environment and the dose of nicotine used.

\section{Materials and methods}

Reagents. Nicotine and lipopolysaccharides (LPS) were obtained from Sigma-Aldrich (St. Louis, MI, USA). Mouse GM-CSF and IL-4 were obtained from R\&D (Minneapolis, MN, USA). Fluorescent-conjugated antibodies were from eBioscience (San Diego, CA, USA). Annexin-V apoptosis detection kit was obtained from Promega (Madison, WI, USA). RPMI-1640 medium, Dulbecco's modified Eagle's medium (DMEM) and fetal bovine serum were purchased from Hyclone (Logan, UT, USA).

Animals. Pathogen-free C57BL/6 mice (female, 6-8 weeks old) were purchased from Shanghai Laboratory Animal Center of the Chinese Academy of Sciences (China) and kept at the Animal Center of Xiamen University. All animal studies were approved by the Review Board of the Medical College of Xiamen University.

Bone marrow-derived murine DCs. Bone marrow-derived DCs were prepared as previously described (11). Briefly, bone marrow mononuclear cells were prepared from bone marrow suspensions by depletion of red cells, and were then cultured at a density of $1 \times 10^{6}$ cells $/ \mathrm{ml}$ in RPMI-1640 medium with $10 \mathrm{ng} / \mathrm{ml}$ of GM-CSF and $1 \mathrm{ng} / \mathrm{ml}$ of IL-4. Non-adherent cells were gently washed out on day 4 of culture; the remaining loosely adherent clusters were used as imDCs. Both imDCs and mature (ma)DCs ( $1 \times 10^{6}$ cells) were firstly starved in RPMI-1640 medium $+0.5 \%$ FCS for $6 \mathrm{~h}$ and exposed to nicotine $(16.5 \mathrm{ng} / \mathrm{ml})$ for $12 \mathrm{~h}$. After washings, the cells were used as nicotine-treated DCs. imDCs were cultured for a further 4 days in the presence of $10 \mathrm{ng} /$ ml LPS and used as maDCs.

Flow cytometric measurement. Expression of cell surface molecules was determine by flow cytometry according to the methods described previously (11). Before staining with relevant $\mathrm{Abs}$, imDCs were incubated for $15 \mathrm{~min}$ at $4^{\circ} \mathrm{C}$ with an antibody to CD16/CD32 at a concentration of $1 \mu \mathrm{g}$ per $1 \times 10^{6}$ cells for blockade of Fc receptors. Staining was performed on ice for $30 \mathrm{~min}$ and then cells were washed with ice-cold PBS, containing $0.1 \% \mathrm{NaN}_{3}$ and $0.5 \%$ BSA. Flow cytometry was carried out with FACSCalibur, and data were analyzed with CellQuest software.

Cell apoptosis assay. Cell apoptosis assay was determined by flow cytometry according to the method described previously (5). For detection of cell apoptosis, DCs were collected from PBS or nicotine-treated imDCs. Cell suspension was washed in PBS and resuspended in binding buffer containing Annexin
V-FITC and propidium iodide (PI) for $20 \mathrm{~min}$ at room temperature. The samples were analyzed on FACSCalibur and data were analyzed with CellQuest software.

Statistical analysis. All data were expressed as the average of experimental data points, and standard error means were determined using the calculated standard deviation of a data set divided by the number of data points within the data set. Statistical significance was tested using the Student's t-test and one-way ANOVA test by Prism software. Differences were considered to be statistically significant at $\mathrm{p}<0.05$.

\section{Results}

Nicotine treatment promotes differentiation of DC precursors into DCs. When cultured in the presence of GM-CSF with IL-4, $\mathrm{DC}$ precursors in the bone marrow differentiated into imDCs, expressing CD11c (12). In order to explore the role of nicotine on DC differentiation, imDCs derived from murine bone marrow were stimulated with nicotine, and the morphology and expression of CD11c were observed by inverted microscopy and flow cytometry, respectively. The results showed that imDCs induced on day 6 grew more branched projections compared to those on day 4 , and the expression of CD11c was also increased from 11.19 to $25.00 \%$ (Fig. 1A). When imDCs of day 4 were stimulated by nicotine $(16.5 \mathrm{ng} / \mathrm{ml})$, more branched projections on imDCs were observed, and the expression of CD11c was up-regulated from 11.19 to $25.68 \%$ (Fig. 1A). Compared to imDCs on day 6 , imDCs on day 4 stimulated with nicotine had more CD11c molecular expression (Fig. 1B, $\mathrm{p}=0.0002$, imDC day $4 \mathrm{vs}$. imDC day $4+\mathrm{Ni} ; \mathrm{p}=0.0005$, imDC day 4 vs. imDC day 6; $=0.0013$, imDC day $4+\mathrm{Ni}$ vs. imDC day 4 ; Fig. $1 \mathrm{C}, \mathrm{p}=0.0009$, imDC day 4 vs. imDC day $4+\mathrm{Ni}$; $\mathrm{p}<0.0001$, imDC day 4 vs. imDC day $6 ; \mathrm{p}=0.0154$, imDC day $4+\mathrm{Ni}$ vs. imDC day 6). Since CD11c is a marker of DCs, the up-regulation of CD11c by nicotine indicated that nicotine enhanced DC differentiation from DC precursors.

Lower doses of nicotine up-regulate the expression of co-stimulatory molecules on imDCs. Several reports have described the controversial effects of nicotine on the expression of DC co-stimulatory molecules $(4-9,13)$. To investigate the effects of nicotine on the expression of co-stimulatory molecules in DCs, imDCs on day 4 were treated with different doses of nicotine $(16.5 \mathrm{ng} / \mathrm{ml}, 25$ and $200 \mu \mathrm{g} / \mathrm{ml})$, and the expression levels of CD80, CD86, CD40 and CD54 were determined by flow cytometry. The results showed that $16.5 \mathrm{ng} / \mathrm{ml}$ of nicotine stimulation obviously increased CD80, CD40 and CD54 molecular expression but decreased CD86 expression on imDCs (Fig. 2B, p=0.0256, imDC control vs. Ni $16.5 \mathrm{ng} / \mathrm{ml}$; Fig. 2D, $\mathrm{p}=0.0098$, imDC control vs. Ni $16.5 \mathrm{ng} / \mathrm{ml}$; Fig. $2 \mathrm{~F}$, $\mathrm{p}=0.0240$, imDC control vs. Ni $16.5 \mathrm{ng} / \mathrm{ml}$; Fig. $2 \mathrm{H}, \mathrm{p}=0.0013$, imDC control vs. Ni $16.5 \mathrm{ng} / \mathrm{ml}) ; 25 \mu \mathrm{g} / \mathrm{ml}$ of nicotine treatment also up-regulated CD86 and CD40 molecular expression (Fig. 2D, p=0.0011, imDC control vs. Ni $25 \mu \mathrm{g} / \mathrm{ml}$; Fig. 2F, $\mathrm{p}=0.0459$, imDC control vs. Ni $25 \mu \mathrm{g} / \mathrm{ml})$. When $200 \mu \mathrm{g} / \mathrm{ml}$ of nicotine was used to stimulate imDCs, down-regulation of both CD80 and CD54, as well as up-regulation of CD40 were observed (Fig. 2B, p=0.0004, Ni $16.5 \mathrm{ng} / \mathrm{ml}$ vs. Ni $200 \mu \mathrm{g} /$ ml; Fig. 2D, p=0.0010, Ni $25 \mu \mathrm{g} / \mathrm{ml}$ vs. Ni $200 \mu \mathrm{g} / \mathrm{ml}$; Fig. $2 \mathrm{~F}$, 
A
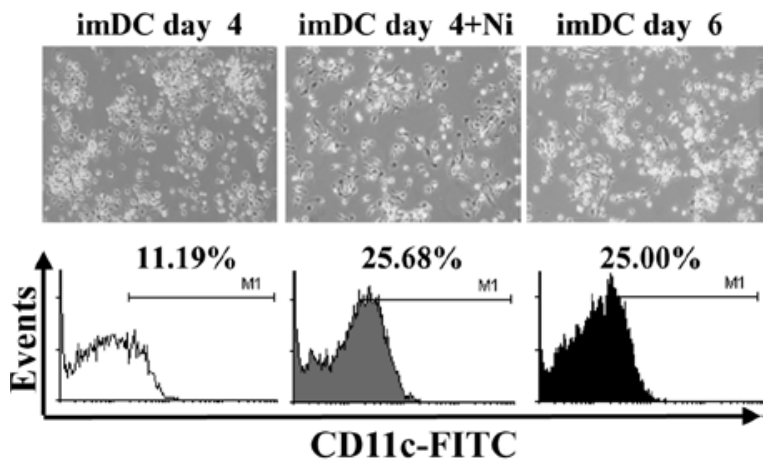

B

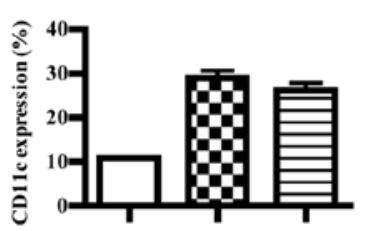

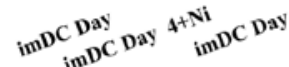

C

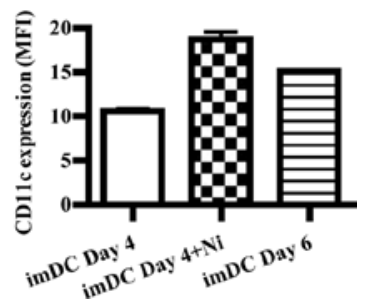

Figure 1. Nicotine promotes murine DC differentiation. DCs induced from murine bone marrow were treated with $16.5 \mathrm{ng} / \mathrm{ml}$ of nicotine for $12 \mathrm{~h}$, then the morphology of DCs was observed by microscopy and CD11c expression was determined by flow cytometry. (A) DC morphology and CD11c expression on day 4, day 4 stimulated with nicotine and day 6. (B) Histographic presentation of percentages of the expression of CD11c $(p=0.0002$, imDC day 4 vs. imDC day $4+\mathrm{Ni} ; \mathrm{p}=0.0005$, imDC day 4 vs. imDC day $6 ; \mathrm{p}=0.0013$, imDC day $4+\mathrm{Ni}$ vs. imDC day). (C) Histographic presentation of MFI on expression of CD11c $(\mathrm{p}=0.0009$, imDC day 4 vs. imDC day $4+\mathrm{Ni} ; \mathrm{p}<0.0001$, imDC day 4 vs. imDC day $6 ; \mathrm{p}=0.0154$, imDC day $4+\mathrm{Ni}$ vs. imDC day). A representative flow cytometric analysis out of 3 is shown; Student's t-test. Ni, nicotine.

$\mathrm{p}<0.0001$, imDC control vs. Ni $200 \mu \mathrm{g} / \mathrm{ml} ; \mathrm{p}<0.0010, \mathrm{Ni}$ $25 \mu \mathrm{g} / \mathrm{ml}$ vs. Ni $200 \mu \mathrm{g} / \mathrm{ml}$; Fig. $2 \mathrm{H}, \mathrm{p}<0.0001$, imDC control vs. Ni $200 \mu \mathrm{g} / \mathrm{ml})$.

Nicotine (16.5 $\mathrm{ng} / \mathrm{ml})$ and LPS co-administration obviously up-regulate co-stimulatory molecules on imDCs. LPS was found to promote DC maturation and to up-regulate co-stimulatory molecules (9). Burgdorf et al reported that LPS activates the TLR4 pathway and increase DC cross-presentation (14). In order to explore the effects of nicotine and LPS on co-stimulatory molecule expression, imDCs on day 4 were stimulated with LPS and nicotine, and the expression of CD80, CD86, CD40 and CD54 was determined by flow cytometry. The results showed that, in the presence of LPS, $16.5 \mathrm{ng} / \mathrm{ml}$ nicotine obviously increased the expression of the co-stimulatory molecules CD80, CD86, CD40 and CD54 on imDCs (Fig. 3A, p<0.0001, imDC control vs. Ni $16.5 \mathrm{ng} / \mathrm{ml}$; $<<0.0001$, Ni $16.5 \mathrm{ng} / \mathrm{ml}$ vs. Ni $25 \mu \mathrm{g} / \mathrm{ml}$; Fig. 3B, p<0.0001, imDC control vs. Ni $16.5 \mathrm{ng} / \mathrm{ml}$; $\mathrm{p}<0.0001$, Ni $16.5 \mathrm{ng} / \mathrm{ml}$ vs. Ni $25 \mu \mathrm{g} / \mathrm{ml}$; Fig. $3 \mathrm{C}, \mathrm{p}<0.0001$, imDC control vs. Ni $16.5 \mathrm{ng} / \mathrm{ml} ; \mathrm{p}<0.0001$, imDC control vs. $\mathrm{Ni} 25 \mu \mathrm{g} / \mathrm{ml}$; Fig. 3D, p<0.0001, imDC control vs. Ni $16.5 \mathrm{ng} /$ $\mathrm{ml} ; \mathrm{p}<0.0001$, imDC control vs. Ni $25 \mu \mathrm{g} / \mathrm{ml})$. In contrast to $16.5 \mathrm{ng} / \mathrm{ml}$ of nicotine stimulation, $200 \mu \mathrm{g} / \mathrm{ml}$ of nicotine obviously decreased CD80, CD86 and CD54 expression; however, increased CD40 expression on imDCs in the presence of LPS was noted (Fig. 3A, p <0.0001, imDC control vs. Ni $200 \mu \mathrm{g} / \mathrm{ml}$; $\mathrm{p}<0.0001$, Ni $25 \mu \mathrm{g} / \mathrm{ml}$ vs. Ni $200 \mu \mathrm{g} / \mathrm{ml}$; Fig. 3B, p=0.0032, Ni
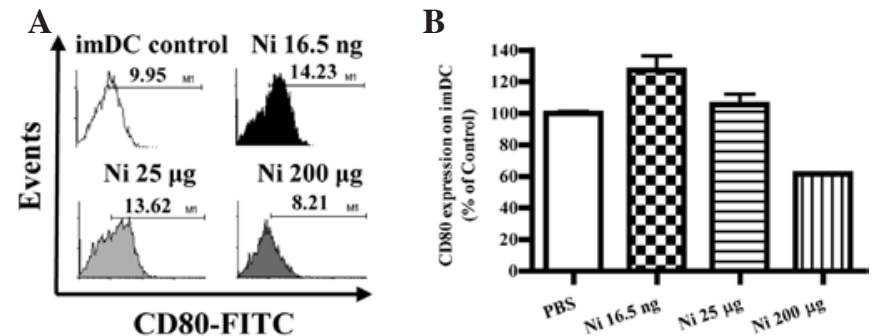

C

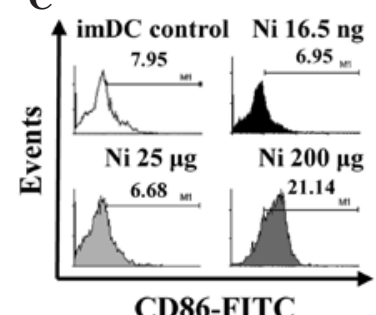

D

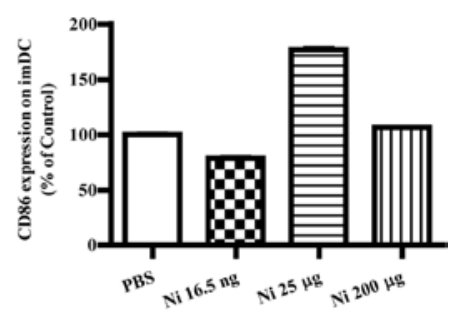

$\mathbf{E}$

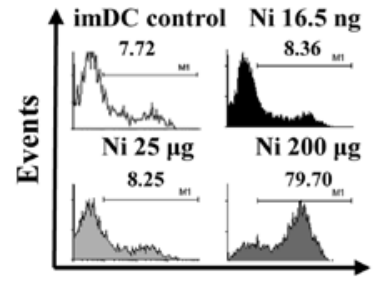

CD40-FITC

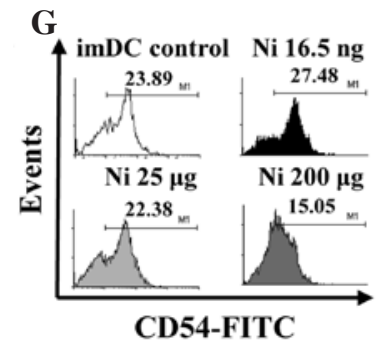

$\mathbf{F}$

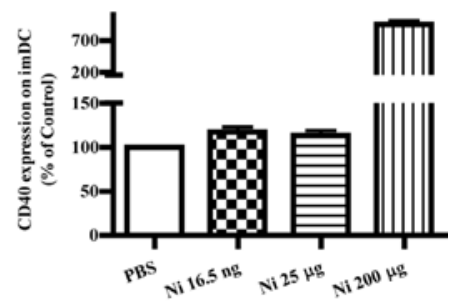

H

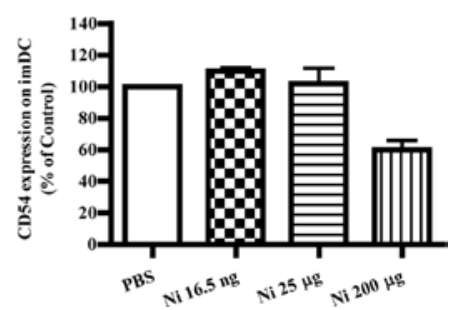

Figure 2. Lower doses of nicotine up-regulate the expression of co-stimulatory molecules on imDCs. imDCs on day 4 induced from murine bone marrow were treated with $16.5 \mathrm{ng} / \mathrm{ml}, 25$ and $200 \mu \mathrm{g} / \mathrm{ml}$ of nicotine for $12 \mathrm{~h}$, and the expression of CD80, CD86, CD40 and CD54 on DCs was determined by flow cytometry. (A) Histographic presentation of CD80 expression on imDCs. (B) CD80 expression on imDCs ( $\mathrm{p}=0.0256$, imDC control vs. Ni $16.5 \mathrm{ng} / \mathrm{ml}$; p=0.0004, Ni $16.5 \mathrm{ng} / \mathrm{ml}$ vs. Ni $200 \mu \mathrm{g} / \mathrm{ml}$ ). (C) Histographic presentation of CD86 expression on imDCs. (D) CD86 expression on imDCs ( $\mathrm{p}=0.0098$, imDC control vs. Ni $16.5 \mathrm{ng} / \mathrm{ml} ; \mathrm{p}=0.0011$, imDC control vs. Ni $25 \mu \mathrm{g} / \mathrm{ml} ; \mathrm{p}=0.0437$, imDC control vs. Ni $200 \mu \mathrm{g} / \mathrm{ml} ; \mathrm{p}=0.0010, \mathrm{Ni} 25 \mu \mathrm{g} / \mathrm{ml}$ vs. $200 \mu \mathrm{g} / \mathrm{ml}$ ). (E) Histographic presentation of CD40 expression on imDCs. (F) CD40 expression on imDCs ( $\mathrm{p}=0.0240$, imDC control vs. Ni $16.5 \mathrm{ng} /$ $\mathrm{ml} ; \mathrm{p}=0.0459$, imDC control vs. Ni $25 \mu \mathrm{g} / \mathrm{ml}$; $\mathrm{p}<0.0001$, imDC control vs. Ni $200 \mu \mathrm{g} / \mathrm{ml} ; \mathrm{p}<0.0010$, Ni $25 \mu \mathrm{g} / \mathrm{ml}$ vs. Ni $200 \mu \mathrm{g} / \mathrm{ml})$. (G) Histographic presentation of CD54 expression on imDCs. (H) CD54 expression on imDCs ( $\mathrm{p}=0.0013$, imDC control vs. Ni $16.5 \mathrm{ng} / \mathrm{ml} ; \mathrm{p}<0.0001$, Ni $16.5 \mathrm{ng} / \mathrm{ml} \mathrm{vs}$. Ni $25 \mu \mathrm{g} / \mathrm{ml} ; \mathrm{p}<0.0001$, imDC control vs. Ni $200 \mu \mathrm{g} / \mathrm{ml})$. A representative flow cytometry analysis out of 3 was shown; Student's t test. Ni, nicotine.

$25 \mu \mathrm{g} / \mathrm{ml}$ vs. Ni $200 \mu \mathrm{g} / \mathrm{ml}$; Fig. 3C, p=0.0004, imDC control vs. Ni $200 \mu \mathrm{g} / \mathrm{ml}$; p=0.0440, Ni $16.5 \mathrm{ng} / \mathrm{ml}$ vs. Ni $200 \mu \mathrm{g} / \mathrm{ml}$; $\mathrm{p}=0.0252$, Ni $25 \mu \mathrm{g} / \mathrm{ml}$ vs. Ni $200 \mu \mathrm{g} / \mathrm{ml}$. Fig. 3D, p<0.0001, imDC control vs. Ni $200 \mu \mathrm{g} / \mathrm{ml})$.

Nicotine has little effect on co-stimulatory molecule expression in mature DCs. With DC maturation, the 
A

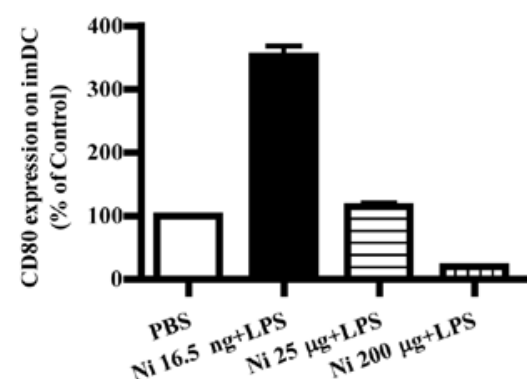

B

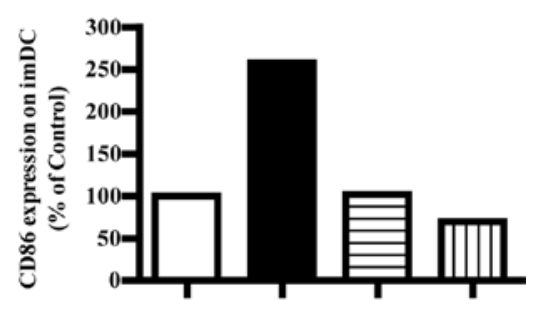

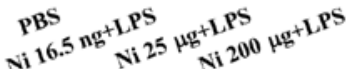

C

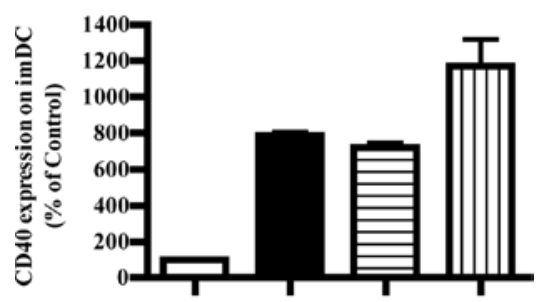

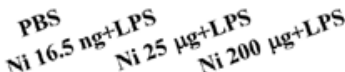

D

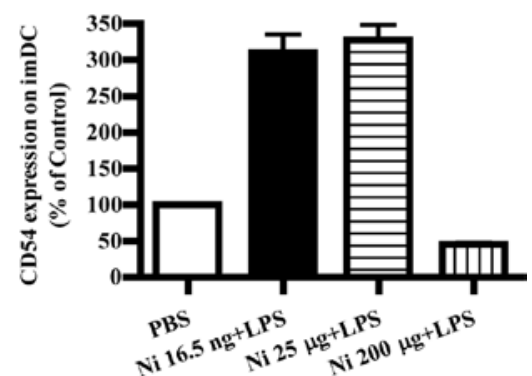

Figure 3. Lower doses of nicotine up-regulate the expression of surface molecules on imDCs in the presence of LPS. imDCs were treated with $16.5 \mathrm{ng} /$ $\mathrm{ml}, 25$ and $200 \mu \mathrm{g} / \mathrm{ml}$ of nicotine in the presence of $100 \mathrm{ng} / \mathrm{ml} \mathrm{LPS} \mathrm{for} 12 \mathrm{~h}$ on day 4 , and then the expression levels of CD80, CD86, CD40 and CD54 on DCs were determined by flow cytometry. (A) CD80 expression on imDCs with different doses of nicotine and LPS stimulation $(\mathrm{p}<0.0001$, imDC control vs. Ni $16.5 \mathrm{ng} / \mathrm{ml} ; \mathrm{p}<0.0001$, imDC control vs. Ni $200 \mu \mathrm{g} / \mathrm{ml} ; \mathrm{p}<0.0001$, Ni $16.5 \mathrm{ng} / \mathrm{ml}$ vs. Ni $25 \mu \mathrm{g} / \mathrm{ml}$; p $<0.0001$, Ni $25 \mu \mathrm{g} / \mathrm{ml}$ vs. Ni $200 \mu \mathrm{g} / \mathrm{ml}$ ). (B) CD86 expression on imDCs with different doses of nicotine and LPS stimulation ( $\mathrm{p}<0.0001$, imDC control vs. Ni $16.5 \mathrm{ng} / \mathrm{ml} ; \mathrm{p}<0.0001$, Ni $16.5 \mathrm{ng} /$ $\mathrm{ml}$ vs. Ni $25 \mu \mathrm{g} / \mathrm{ml} ; \mathrm{p}=0.0032$ and $\mathrm{Ni} 25 \mu \mathrm{g} / \mathrm{ml}$ vs. Ni $200 \mu \mathrm{g} / \mathrm{ml}$ ). (C) CD40 expression on imDCs with different doses of nicotine and LPS stimulation $(\mathrm{p}<0.0001$, imDC control vs. Ni $16.5 \mathrm{ng} / \mathrm{ml} ; \mathrm{p}<0.0001, \mathrm{imDC}$ control vs. $\mathrm{Ni}$ $25 \mu \mathrm{g} / \mathrm{ml} ; \mathrm{p}=0.0004$, imDC control vs. Ni $200 \mu \mathrm{g} / \mathrm{ml} ; \mathrm{p}=0.0440$, Ni $16.5 \mathrm{ng} /$ $\mathrm{ml}$ vs. Ni $200 \mu \mathrm{g} / \mathrm{ml} ; \mathrm{p}=0.0252$, Ni $25 \mu \mathrm{g} / \mathrm{ml}$ vs. Ni $200 \mu \mathrm{g} / \mathrm{ml}$ ). (D) CD54 expression on imDCs with different doses of nicotine and LPS stimulation $(\mathrm{P}<0.0001$, imDC control vs. Ni $16.5 \mathrm{ng} / \mathrm{ml} ; \mathrm{p}<0.0001$, imDC control vs. $\mathrm{Ni}$ $25 \mu \mathrm{g} / \mathrm{ml} ; \mathrm{p}<0.0001$, imDC control vs. Ni $200 \mu \mathrm{g} / \mathrm{ml}$ ). A representative flow cytometric analysis out of 3 is shown; Student's t test. Ni, nicotine.

co-stimulatory molecules were up-regulated accordingly. Mature immunogenic DCs were found to induce Th1 and Th2 cell differentiation, and/or CTL priming, depending on

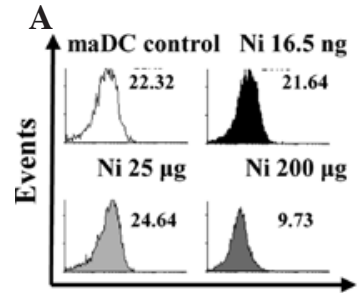

CD80-FITC

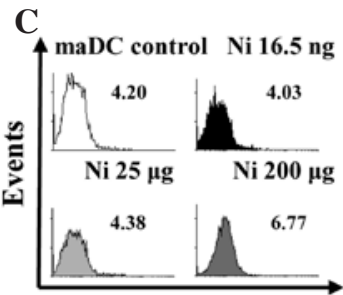

CD86-FITC

E
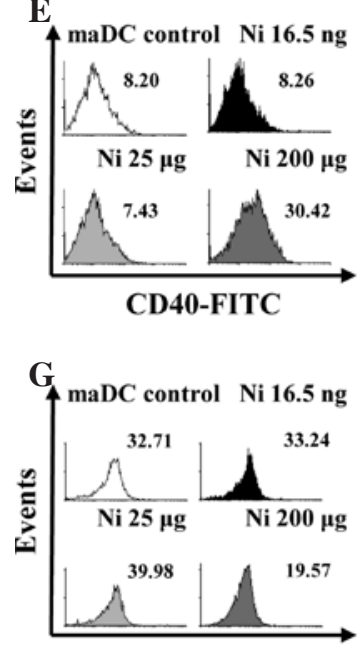

CD54-FITC
B

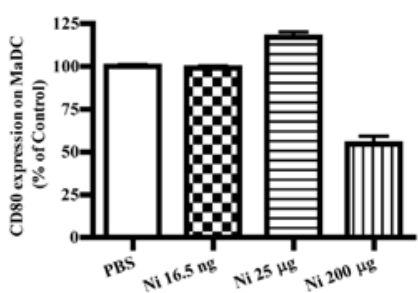

D
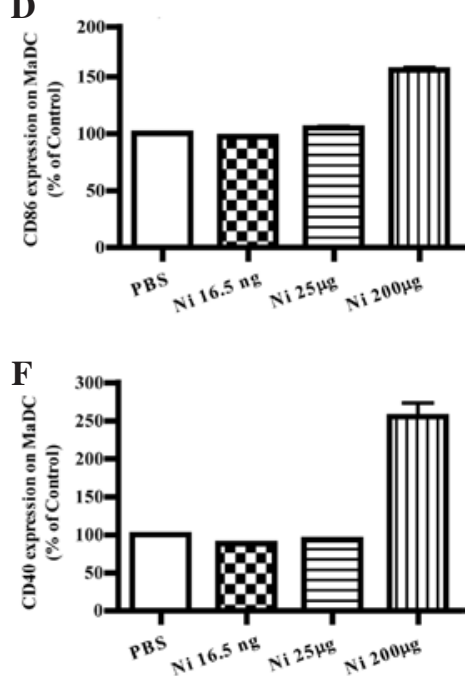

$\mathbf{H}$

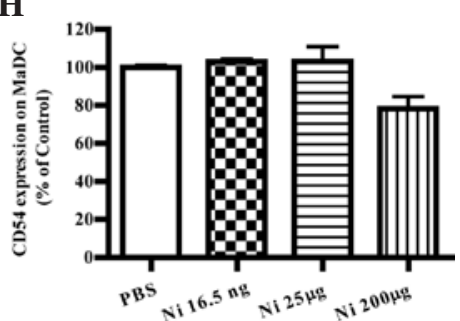

Figure 4. The doses of nicotine determine the expression of surface molecules on maDCs. At day 4 , imDCs induced from murine bone marrow were treated with $10 \mathrm{ng} / \mathrm{ml} \mathrm{LPS} \mathrm{for} \mathrm{a} \mathrm{further} 4$ days and were considered as mature DCs (maDCs). maDCs were stimulated with $16.5 \mathrm{ng} / \mathrm{ml}, 25$ and $200 \mu \mathrm{g} / \mathrm{ml}$ of nicotine for $14 \mathrm{~h}$, and the expression levels of CD80, CD86, CD40 and CD54 were determined by flow cytometry. (A) Histographic presentation of CD80 expression on maDCs. (B) CD80 expression on maDCs $(\mathrm{p}=0.0256$, imDC control vs. Ni $16.5 \mathrm{ng} / \mathrm{ml} ; \mathrm{p}=0.0004$, Ni $16.5 \mathrm{ng} / \mathrm{ml}$ vs. Ni $200 \mu \mathrm{g} /$ $\mathrm{ml}$ ). (C) Histographic presentation of CD86 expression on maDCs. (D) CD86 expression on maDCs ( $\mathrm{p}=0.0098$, imDC control vs. Ni $16.5 \mathrm{ng} / \mathrm{ml} ; \mathrm{p}=0.0011$, imDC control vs. Ni25 $\mu \mathrm{g} / \mathrm{ml} ; \mathrm{p}=0.0437$, imDC control vs. Ni $200 \mu \mathrm{g} / \mathrm{ml}$; $\mathrm{p}=0.0010$, Ni $25 \mu \mathrm{g} / \mathrm{ml}$ vs. Ni $200 \mu \mathrm{g} / \mathrm{ml}$ ). (E) Histographic presentation of CD40 expression on maDCs. (F) CD40 expression on maDCs $(\mathrm{p}=0.0240$, imDC control vs. Ni $16.5 \mathrm{ng} / \mathrm{ml} ; \mathrm{p}=0.0459$, imDC control vs. Ni $25 \mu \mathrm{g} / \mathrm{ml}$; $\mathrm{p}<0.0001$, imDC control vs. Ni $200 \mu \mathrm{g} / \mathrm{ml} ; \mathrm{p}<0.0010$, Ni $25 \mu \mathrm{g} / \mathrm{ml}$ vs. Ni $200 \mu \mathrm{g} / \mathrm{ml}$ ). (G) Histographic presentation of CD54 expression on maDCs. (H) CD54 expression on maDCs ( $\mathrm{p}=0.0013$, imDC control vs. Ni $16.5 \mathrm{ng} /$ $\mathrm{ml} ; \mathrm{p}<0.0001$, Ni $16.5 \mathrm{ng} / \mathrm{ml}$ vs. Ni $25 \mu \mathrm{g} / \mathrm{ml} ; \mathrm{p}<0.0001$, imDC control vs. $\mathrm{Ni} 200 \mu \mathrm{g} / \mathrm{ml}$ ). A representative flow cytometry analysis out of 3 is shown; Student's t test. Ni, nicotine.

the nature of the maturation signal they received, as well as the constraints imposed by ontogeny and/or environment modifiers (10). Although nicotine increased co-stimulatory molecule expression on imDCs, its effects on co-stimulatory molecule expression of mature DCs is little known. To investigate the effects of nicotine on mature DC co-stimu- 


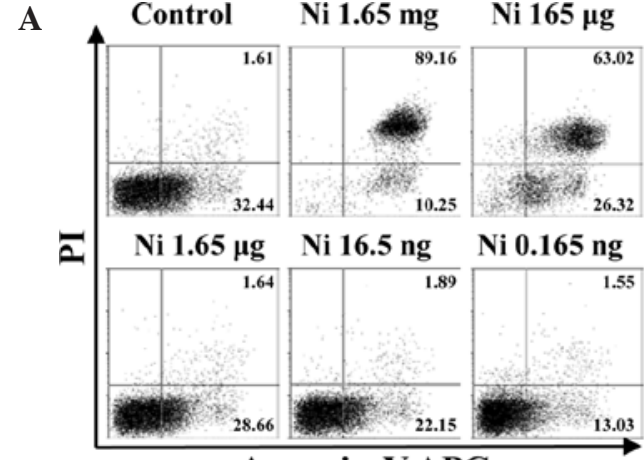

Annexin-V APC
B

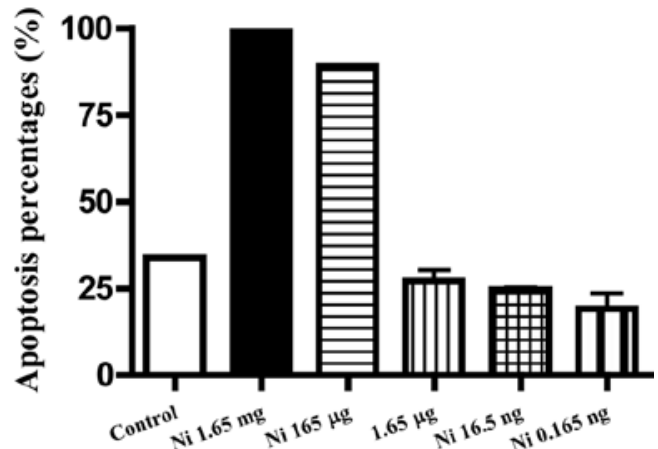

Figure 5. The pro- or anti-apoptotic effects of nicotine on imDCs are dependent on the dose of nicotine. On day 4, imDCs were treated with different doses of nicotine for a further $12 \mathrm{~h}$, and the viability of imDCs was determined by flow cytometry using FITC-labeled Annexin V and propidium iodide (PI). (A) Histographic presentation of flow cytometric data. (B) Histographic presentation of A. p $<0.0001$, imDC control vs. Ni 1.65 mg/mm, 16.5 ng/ml; p $<0.0001$, imDC control vs. $165 \mu \mathrm{g} / \mathrm{ml} ; \mathrm{p}=0.0046$, imDC control vs. Ni $16.5 \mathrm{ng} / \mathrm{ml} ; \mathrm{p}=0.0405$, imDC control vs. Ni $0.165 \mathrm{ng} / \mathrm{ml}$. Data represent the mean \pm SEM, $\mathrm{n}=4$. A representative flow cytometric analysis out of 3 is shown; Student's t test. Ni, nicotine.

latory molecule expression, DCs induced from murine bone marrow were matured by LPS first and further stimulated with nicotine. The results showed that, $16.5 \mathrm{ng} / \mathrm{ml}$ of nicotine stimulation decreased the expression of CD80, CD86 and CD40 but increased CD54 expression on mature DCs (Fig. 4B, p=0.0256, imDC control vs. Ni $16.5 \mathrm{ng} / \mathrm{ml}$; Fig. 4D, $\mathrm{p}=0.0098$, imDC control vs. Ni $16.5 \mathrm{ng} / \mathrm{ml}$; Fig. 4F, p=0.0240, imDC control vs. Ni $16.5 \mathrm{ng} / \mathrm{ml}$; Fig. $4 \mathrm{H}, \mathrm{p}=0.0013$, imDC control vs. Ni $16.5 \mathrm{ng} / \mathrm{ml})$. In contrast to $16.5 \mathrm{ng} / \mathrm{ml}$ of nicotine stimulation, $25 \mu \mathrm{g} / \mathrm{ml}$ nicotine stimulation obviously augmented the expression of CD80 and CD86 on mature DCs (Fig. 4B, p=0.0004, Ni $16.5 \mathrm{ng} / \mathrm{ml}$ vs. Ni $200 \mu \mathrm{g} / \mathrm{ml}$; Fig. 4D, $\mathrm{p}=0.0011$, imDC control vs. Ni $25 \mu \mathrm{g} / \mathrm{ml}$ ).

The pro- or anti-apoptotic effects of nicotine on imDCs were dose-dependent. As nicotine is thought to be toxic to cells, the viabilities of imDCs stimulated with different doses of nicotine were quantitated by flow cytometry using FITC-labeled Annexin V and PI. The results showed that, 16.5-0.165 ng/ml of nicotine had no effect on inducing DC apoptosis, but higher doses of nicotine stimulation induced more than $90 \%$ cell apoptosis at the dose of $1.65 \mathrm{mg} / \mathrm{ml}$ and $165 \mu \mathrm{g} / \mathrm{ml}$ (Fig. 5B, $\mathrm{p}<0.0001$, imDC control vs. Ni $1.65 \mathrm{mg} / \mathrm{ml} ; \mathrm{p}<0.0001$, imDC control vs. Ni $165 \mu \mathrm{g} / \mathrm{ml})$. In contrast to $1.65 \mathrm{mg} / \mathrm{ml}$ and $165 \mu \mathrm{g} / \mathrm{ml}$ of nicotine, $16.5-0.165 \mathrm{ng} / \mathrm{ml}$ of nicotine treatment revealed an anti-apoptotic effect on imDCs (Fig. 5B p $=0.0046$, $\mathrm{imDC}$ control vs. Ni $16.5 \mathrm{ng} / \mathrm{ml} ; \mathrm{p}=0.0405$, imDC control vs. $\mathrm{Ni} 0.165 \mathrm{ng} / \mathrm{ml})$.

\section{Discussion}

In the past few years, a number of reports have documented the biological effects of nicotine on DCs (4-9). Aicher et al (5) reported that nicotine dose-dependently enhanced DC co-stimulatory molecule expression, enhanced IL-12 and IL-10 release, and augmented the T cell priming ability of DCs. Our previous studies not only characterized that nicotine has stimulatory effects on imDCs, but also confirmed that nicotine-treated DCs exhibit anti-tumor effects $(6,7)$. In contrast, Nouri-Shirazi et al (8) reported that, in the presence of nicotine, monocyte-derived DCs manifested lower endo- cytic and phagocytic activities, produced decreased levels of proinflammatory cytokines, and had a reduced ability to stimulate antigen-presenting cell-dependent $\mathrm{T}$ cell responses. Further studies found that nicotine altered the biological activities of developing mouse bone marrow-derived DCs (9). Vassalo et al (13) found that cigarette smoke extract (CSE), although not nicotine, suppressed the DC-mediated priming of $\mathrm{T}$ cells in a mixed lymphocyte reaction (MIR). Hence, there is a controversial conclusion regarding the exact role of nicotine on DCs. Kawashima et al reported that short-term exposure to nicotine enhanced lymphocyte c-fos gene expression, but longterm exposure down-regulated $\mathrm{nAchR}$ mRNA expression (15). In a fetal thymus organ culture model, Middlebrook et al found that low levels of nicotine $\left(10^{-18}-10^{-4} \mathrm{M}\right)$ increased the number of immature $\mathrm{T}$ cells, but a higher dose $\left(>10^{-4} \mathrm{M}\right)$ inhibited $\mathrm{T}$ cell development (16). The controversy regarding the effects of nicotine on imDCs may be attributed to the differences in experimental design, species, duration of exposure and particularly the nicotine concentration used in these experiments.

In the present study, we demonstrate that different doses of nicotine have obviously different effects in inducing DC apoptosis. High concentrations of nicotine $(1.65 \mathrm{mg} / \mathrm{ml}$ and $165 \mu \mathrm{g} / \mathrm{ml}$ ) were found to be toxic, leading to low cell viability (Fig. 5). When $1.65 \mathrm{mg} / \mathrm{ml}$ of nicotine was used to stimulate imDCs, nearly all cells were undergoing apoptosis. There was no surprise to find that $200 \mu \mathrm{g} / \mathrm{ml}$ of nicotine decreased the expression of CD80 and CD86 on imDCs (Fig. 2) and supressed the proliferation of DC-mediated T cells (8). Aicher et al and our previous studies treated DCs with nicotine $16.5 \mathrm{ng} / \mathrm{ml}$ for 12 h, while Nourii-Shirazi et al stimulated DCs with nicotine at a final concentration of $200 \mu \mathrm{g} / \mathrm{ml}$ for $48 \mathrm{~h}$, respectively, approximately 10,000 -fold higher compared to the concentration of $16.5 \mathrm{ng} / \mathrm{ml}(5-8)$. With $10 \mu \mathrm{g} / \mathrm{ml}$ of nicotine treatment, Vassalo et al (13) also acquired similar results of co-stimulatory molecule expression to Aicher's data. Actually, Vassalo et al found that nicotine as opposed to CSE, failed to inhibit DC-induced $\mathrm{T}$ cell priming, to suppress the inflammatory up-regulation of co-stimulatory molecules and the expression of chemotactic cytokine receptor 7 (CCR7) on either imDCs or LPS-matured DCs (13). Since serum nicotine levels in smokers are usually within the range of 10-100 $\mathrm{ng} / \mathrm{ml}$, never exceeding 
the amount $100 \mu \mathrm{g} / \mathrm{ml}$ in vivo (17), the physiological relevance that nicotine suppresses certain DC responses remains uncertain (5).

Immunity requires DC maturation induced by microbial endotoxins such as LPS, which increase the expression of costimulatory molecules on the DC surface $(18,19)$. Our present study showed that lower doses of nicotine influenced DC maturation and differentiation as revealed by the up-regulation of costimulatory molecules CD80, CD40 and CD11c. In the presence of LPS, in contrast to the $200 \mu \mathrm{g} / \mathrm{ml}$ of nicotine, $16.5 \mathrm{ng} / \mathrm{ml}$ of nicotine stimulation obviously up-regulated the expression of molecules CD80, CD86, CD40 and CD54 (Fig. 3). Consistent with our results, Aicher et al reported that nicotine strongly activates DC-mediated adaptive immunity (5). They demonstrated that mouse bone marrow-derived competent DCs exposed to $16.5 \mathrm{ng} / \mathrm{ml}$ of nicotine alone express higher levels of MHCs and costimulatory molecules compared to the control DCs and have a greater capacity to stimulate ovalbumin (OVA)-specific T cell proliferation (5). Conversely, Nouri-Shirazi et al reported that nicotine-treated human DCs display an increased capacity for antigen uptake, fail to fully up-regulate MHCs, hardly express CCR7 and display profoundly reduced Th1 promoting capacity (8). But, interestingly, their further studies showed that while the presence of nicotine in the microenvironment has no direct effect on competent mouse bone marrow-derived DC function, it promotes the development of mouse bone marrowderived DC precursors into DCs with a semi-mature phenotype revealed by higher expression of costimulatory molecules CD80, CD86, CD40 and MHC II molecules and CCR7, and supports the proliferation and differentiation of OVA-specific naïve T cells into effector memory cells (9). The differences in the DC preparations and treatments might account for the discrepancies observed between ours and their studies. It is worth mentioning that, when human monocyte-derived imDCs (day 6) and murine bone marrow-derived imDCs (day 4) were used by Nouri-Shirazi et al to study the effects of nicotine on DC-mediated $\mathrm{T}$ cell priming, the conclusions were obviously different. From our results, it appears that all of the factors of the nicotinic microenvironment, nicotine doses used in the experiment and DC maturation status, affect the functions of DCs.

The data presented in this report offer new information regarding the immunological alterations associated with nicotine, particularly at the level of mouse DC differentiation. This finding is important as it provides a rationale for further investigation of the mechanisms by which nicotine influences DCs in vivo and consequently hosts immunity using animal models.

\section{Acknowledgements}

The authors would like to thank Professor X.T. Cao (Second Military Medical University, Shanghai, China) and Y.H. Chen (University of Pennsylvania, Philadelphia, USA) for kindly providing the Hepa 1-6 cell lines and polishing the manuscript. In addition, we thank Jin Hua Su and Fu Chen for their excellent animal care. This study was supported by grants from the Natural Science Foundation of Fujian Province of China (no. 2008J0112), the Natural Science Foundation of Xiamen (no. 3502Z20104002) and the Xiamen Science and Technology Key program (no. 3502Z20100006).

\section{References}

1. Avila J and Diaz-Nido J: Tangling with hypothermia. Nat Med 10: 460-461, 2004.

2. Mandavilli A: Nicotine fix. Nat Med 10: 660-661, 2004

3. Libert C: Inflammation - a nervous connection. Nature 421: 328-329, 2003.

4. Guinet EK, Yoshida M and Nouri-Shirazi: Nicotinic environment affects the differentiation and functional maturation of monocytes derived dendritic cells (DCs). Immunol Lett 95: 45-55, 2004.

5. Aicher AC, Heeschen M, Mohanpt JP, Cooke AM, Zeihe AM and Dimmeler S: Nicotine strongly activates dendritic cellmediated adaptive immunity: potential role for progression of atherosclerotic lesions. Circulation 107: 604-611, 2003.

6. Gao FG, Wan DF and Gu JR: Ex vivo nicotine stimulation augments the efficacy of therapeutic bone marrow-derived dendritic cell vaccination. Clin Cancer Res 13: 3706-3712, 2007.

7. Gao FG, Li HT, Li ZJ and Gu JR: Nicotine stimulated dendritic cells could achieve anti-tumor effects in mouse lung and liver cancer. J Clin Immunol 31: 80-88, 2011.

8. Nouri-Shirazi M and Guinet E: Evidence for the immunosuppressive role of nicotine on human dendritic cell functions. Immunology 109: 365-373, 2003.

9. Nouri-Shirazi M, Tinajero R and Guinet E: Nicotine alters the biological activities of developing mouse bone marrow-derived dendritic cells (DCs). Immunol Lett 109: 155-164, 2007.

10. Hanna ST: Nicotine effect on cardiovascular system and ion channels. J Cardiovasc Pharmacol 47: 348-358, 2006.

11. Zhang MH, Tang H, Guo ZH, An HZ, Zhu XJ, Song WG, Guo J, Huang X, Chen TY, Wang JL and Cao XT: Splenic stroma drives mature dendritic cells to differentiate into regulatory dendritic cells. Nat Immunol 5: 1124-1133, 2004.

12. Shortman K and Liu YJ: Mouse and human dendritic cell subtypes. Nat Rev Immunol 2: 151-161, 2002.

13. Vassallo R, Tamada K, Lau JS, Kroening PR and Chen L: Cigarette smoke extract suppresses human dendritic cell function leading to preferential induction of Th-2 priming. J Immunol 175: 2684-2691, 2005.

14. Burgdorf S, Kautz A, Böhnert V, Knolle PA and Kurts C: Distinct pathways of antigen uptake and intracellular routing in CD4 and CD8 T cell activation. Science 316: 612-616, 2007.

15. Kawashima and Fujii KT: The lymphocytic cholinergic system and its contribution to the regulation of immune activity. Life Sci 74 : 675-696, 2003.

16. Middlebrook AJ, Martina C, Chang Y, Lukas RJ and Deluca D: Effects of nicotine exposure on T cell development in fetal thymus organ culture: arrest of T cell maturation. J Immunol 169: 2915-2924, 2002.

17. Matsunaga K, Klein TW, Friedman H and Yamamoto Y: Involvement of nicotinic acetylcholine receptors in suppression of antimicrobial activity and cytokine responses of alveolar macrophages to Legionella pneumophila infection by nicotine. J Immunol $167:$ 6518-6524, 2001.

18. Abele R and Tampe R: The ABCs of immunology: structure and function of TAP, the transporter associated with antigen processing. Physiology (Bethesda) 19: 216-224, 2004.

19. Ackerman AL and Cresswell P: Cellular mechanisms governing cross-presentation of exogenous antigens. Nat Immunol 5: 678-684, 2004. 